\title{
Hydrogen-bonding interactions and compostability of bionanocomposite films prepared from corn starch and nano-fillers with and without added Jamaica flower extract
}

\author{
Tomy J. Gutiérrez ${ }^{\mathrm{a}, *}$, Luis A. Toro-Márquez ${ }^{\mathrm{a}, \mathrm{b}}$, Danila Merino ${ }^{\mathrm{a}}$, Julieta R. Mendieta ${ }^{\mathrm{c}}$ \\ a Grupo de Materiales Compuestos Termoplásticos (CoMP), Instituto de Investigaciones en Ciencia y Tecnología de Materiales (INTEMA), Facultad de Ingeniería, \\ Universidad Nacional de Mar del Plata (UNMdP) y Consejo Nacional de Investigaciones Científicas y Técnicas (CONICET), Colón 10850, B7608FLC, Mar del Plata, \\ Argentina \\ ${ }^{\mathrm{b}}$ Grupo de Polímeros, Departamento de Ciencia de los Materiales, Universidad Simón Bolívar (USB), Apartado 89000, Caracas 1080-A, Venezuela \\ ${ }^{\mathrm{c}}$ Grupo de Fisiología del Estrés en Plantas, Instituto de Investigaciones Biológicas (IIB), Facultad de Ciencias Exactas y Naturales, Universidad Nacional de Mar del Plata \\ (UNMdP), Consejo Nacional de Investigaciones Científicas y Técnicas (CONICET) y Comisión de Investigaciones Científicas (CIC), Deán Funes 3250, B7602AYJ, Mar del \\ Plata, Argentina
}

\section{A R T I C L E I N F O}

\section{Keywords:}

Biodegradability

Eco-friendly materials

Food packaging

$\mathrm{pH}$-sensitive bionanocomposite

\begin{abstract}
A B S T R A C T
Bionanocomposite films processed by twin screw extrusion followed by thermo molding were prepared from corn starch (Zea mays) and pH-sensitive nano-clays packaged with Jamaica flower (Hibiscus sabdariffa) extract (JFE). The hydrogen (H)-bonding interactions of the materials obtained were evaluated by ATR/FTIR spectroscopy, and their influence on the physicochemical and surface properties of the materials was analyzed. The degree of biodegradability and compostability of the films was also recorded. This latter was analyzed in terms of the ecotoxicity of the films using the variations in the growth of the primary root of lettuce (Lactuca sativa) seedlings exposed to three concentrations $(1,10$ and $100 \mu \mathrm{g} / \mathrm{mL})$ of the powdered films as a biomarker. The addition of the JFE-containing nano-fillers strengthened the H-bonding interactions with the thermoplastic starch (TPS) matrix, and these interactions were more efficient when there were fewer steric impediments between the JFE and the TPS. Additionally, stronger H-bonding interactions produced more hydrophilic surfaces, with greater surface energy and rougher surface morphology. All the films tested were biodegradable. Our research group had previously encountered high cytotoxicity in one of the evaluated nano-clay systems, and in this study, we confirmed that this same nano-clay system produced a non-compostable material at high concentrations $(100 \mu \mathrm{g} / \mathrm{mL})$, as measured by its effect on lettuce seedlings. This confirms that biodegradable materials are not necessarily compostable.
\end{abstract}

\section{Introduction}

The growing global concern about environmental pollution caused by the accumulation of petroleum-derived plastics has led to the search for novel, natural and biodegradable polymers to replace them (Gao et al., 2014; Zhang, Wang, Zhao, \& Wang, 2013). Ideally, a novel plastic material should be eco-friendly and low cost whilst maintaining a comparable performance to conventional plastic materials (Iman \& Maji, 2012; Romero-Bastida, Bello-Pérez, Velazquez, \& AlvarezRamirez, 2015). Among the food hydrocolloids commonly used in the food and polymers industry is starch (Iman \& Maji, 2012; Zhang et al., 2013). In general, starch has a granular form and is composed of amylose and amylopectin (Suárez \& Gutiérrez, 2017). The high temperatures and shear stresses of extrusion processing conditions disrupt the starch granules (Hernández, Emaldi, \& Tovar, 2008), exposing the amylose and amylopectin to the medium and resulting in thermoplastic starch (TPS) (Iman \& Maji, 2012; Romero-Bastida et al., 2015). It is worth noting that corn starch (Zea mays) has been given special attention because it is produced all over the world (Gutiérrez, Tapia, Pérez, \& Famá, 2015).

Although starch films offer some good physical characteristics such as being colorless, odorless and with adequate barrier properties against oxygen (Yan, Hou, Guo, \& Dong, 2012), their use has been limited by their hydrophilicity and brittleness (Iman \& Maji, 2012). In order to

\footnotetext{
* Corresponding author. Institute of Research in Materials Science and Technology, Faculty of Engineering, National University of Mar del Plata and National Scientific and Technical Research Council (CONICET), PO Box B7608FLC, Colón 10850, Mar del Plata, Argentina.

E-mail address: tomy.gutierrez@fi.mdp.edu.ar (T.J. Gutiérrez).
} 
overcome these drawbacks some starches have been chemically modified, and natural and derived (reinforcing) fillers added. It has been reported that adding small amounts of layered silicates (nano-clays) as natural fillers to polymers improves their mechanical, thermal and barrier properties (Chung et al., 2010). All these improvements are a consequence of the nanometric size of the clay sheets, which increases the surface area of the filler. This improves the interactions between it and the matrix, making the components of the developed materials more compatible with each other (Iman \& Maji, 2012). The kind of clay most commonly used for reinforcement is the montmorillonite (Mnt) and its organically modified derivatives. Mnt is a hydrophilic stratified mineral with ion exchange properties. These features make it a good candidate for the intercalation of the hydrophilic starch chains between the clay layers. In addition, the degree of penetration of the polymer chains within the galleries of the nano-clay can be modified due to physical or chemical modifications of either the natural (clay) filler or the starch. The properties of the resulting material depend on factors such as the degree of diffusion and molecular weight of the polymer, the type of clay used, the relative concentrations of the clay, and the polarities of both compounds (Romero-Bastida et al., 2015). In addition, the structure and properties of the natural fillers may be significantly altered by the modification of either the matrix or the nanoclay material (Gao et al., 2014). For example, the organic modification of nano-clays can increase the interlayer spacing between the clay sheets, favoring the intercalation of the polymer chains (Gao et al., 2014).

Recently, pH-sensitive (intelligent) nano-clays obtained from natural or modified Mnt with and without nanopacked Jamaica flower extract (JFE) have been characterized by our research group (Gutiérrez, León, Ponce, \& Alvarez, 2018). The idea of obtaining these pH-sensitive nano-clays was to develop nano-clay reinforced food packaging materials based on food hydrocolloids that not only protect the packaged food, but also indicate its degree of freshness, any fraudulent modifications, or the rupture of the cold chain of the food (Bracone, Merino, González, Alvarez, \& Gutiérrez, 2016; Gutiérrez, Herniou-Julien, Álvarez, \& Alvarez, 2018; Gutiérrez \& Alvarez, 2018; Gutiérrez, Suniaga, Monsalve, \& García, 2016). However, in a previous study we found that the extrusion process caused the exfoliation of the pH-sensitive nano-clays, thus leaving the nano-packaged pigment exposed to "high temperatures" (around $110^{\circ} \mathrm{C}$ ) which led to their degradation (Toro-Márquez, Merino, \& Gutiérrez, 2018). In addition, one of the nano-clay systems (Mnt modified with dimethyl benzylhydrogenated tallow ammonium, MntMB) showed high cytotoxicity at two different doses $(0.25 \% \mathrm{w} / \mathrm{v}$ and $0.5 \% \mathrm{w} / \mathrm{v})$ using the normal human lung fibroblast (MRC-5, ATCC CCL-171)-cell line as a test material (see Appendix A and B) (Gutiérrez, León, et al., 2018). These results led us to ask further important, and as yet unanswered, questions: 1) Could this high cytotoxicity put at risk the compostability of the material? Although these types of material are considered to be biodegradable (Lee et al., 2002), this does not mean that they are compostable or ecofriendly, and 2) Could the concentrations of this material in soil cause damage to the natural vegetation, the soil itself or food crops? A review of the literature showed that only a few studies have investigated the biodegradability of materials derived from food hydrocolloids or carbohydrate polymers, and only one recent study, carried out by our research group (Gutiérrez, León, et al., 2018) who used a novel bioassay employing the furniture weevil (Tricorynus sp, Coleoptera: Anobiidae), has determined the non-compostability of a bio-polymer film, in this case prepared from methylated pumpkin flour, even although this material is considered to be biodegradable according to existing international regulations (EN 13432, 2000; ASTM D5338 - 98, 2003; ISO 14855-1:2005, 2005; EN 14995, 2006; ISO 14855-2:2007, 2007). This means that some biodegradable materials are non-compostable, i.e. they can cause serious problems due to their ecotoxicity, and thus cannot be considered as "green" or eco-friendly. According to the ASTM D6400 (2004) standard, methods for the evaluation of the compostablity (ecotoxicity) of polymers are mainly based on the use of plants, aquatic fauna (Daphnia), algae (green algae), soil fauna (earthworms) and microbes (luminescent bacteria). Nonetheless, we propose another simple approach to evaluate the ecotoxicity of a polymer using differences in the percent primary root growth of lettuce (Lactuca sativa) seedlings germinated on $0.8 \%$ agar- $\mathrm{H}_{2} \mathrm{O}$ in Petri plates.

The hypotheses of this research study were: 1) hydrogen $(\mathrm{H})$ bonding interactions in bionanocomposite films made from (nano-clay) natural filler/starch could improve the properties, particularly the surface properties, of the resulting material, and 2) the growth of the lettuce root could be used as a biomarker for the evaluation of the compostability of the developed materials, i.e. the (nano-clay) filler used to reinforce the polymeric matrix could impair the growth of the lettuce root. Based on these hypotheses we aimed to: 1) study the $\mathrm{H}$ bonding interactions particularly those that occur on the surface of the material, and 2) assess the biodegradability and compostability of the materials developed using the percent growth of the primary root of lettuce seedlings exposed to different concentrations of the obtained materials as a biomarker.

The novelty of this study lies in: 1) the use of $\mathrm{pH}$-sensitive nanoclays as natural fillers of food hydrocolloid matrix used (corn starch), 2) the processing methodology used: extrusion followed by thermo compression (large-industrial scale) which has been little studied as compared to the casting methodology (small-laboratory scale) that has been well studied over many years, 3) the examination of the H-bonding interactions that occur on the surfaces of these types of materials, which has been little studied, and 4) the determination of the compostability (ecotoxicity) of these materials using a novel bioassay.

\section{Experimental}

\subsection{Materials}

Corn starch (Zea mays), glycerol, and several montmorillonites (Mnt) were used as the carbohydrate polymer, plasticizer and nanofillers, respectively, for the preparation of the bionanocomposite films. Corn starch was purchased from the Distribuidora Dos Hermanos, Mark Ying Yang (Mar del Plata, Argentina). Glycerol was obtained from Aurum (Mar del Plata, Argentina). The nano-clays used as nano-fillers in this study were natural Mnt (NMnt, or HPS according to the manufacturer), Mnt modified with dimethyl benzylhydrogenated tallow ammonium (MntMB, denominated 43B by the manufacturer) and Mnt modified with dimethyl dihydrogenated tallow ammonium (MntMD, or $72 \mathrm{~T}$ according to the manufacturer). All the nano-clays tested were supplied by Laviosa Chimica Mineraria S.p.A. (Livorno, Italy) and were used as received. Following the manufacturer's descriptions, these modified Mnts are nano-clays prepared from a naturally occurring Mnt, purified and modified with quaternary ammonium salts (dimethyl benzylhydrogenated tallow ammonium and dimethyl dihydrogenated tallow ammonium). Jamaica flower (Hibiscus sabdariffa) extract (100\% anthocyanin) was obtained according to the procedure described by Gutiérrez, León, et al. (2018). Briefly, dehydrated flowers were purchased from a local market in the Ciudad Autónoma de Buenos Aires, Provincia de Buenos Aires, Argentina. The flowers are marketed by an Argentine company and labeled as harvested in the Jardín America (Street Amado Nervo 478, Provincial de Misiones, Argentina; geographical coordinates - latitude S $27^{\circ} 2^{\prime} 25.597^{\prime \prime}$ and longitude W $55^{\circ}$ $14^{\prime} 22.906^{\prime \prime}$ ). The extract was obtained by weighing $30 \mathrm{~g}$ of Jamaica flowers and then immersing them in $200 \mathrm{~mL}$ of ethanol (Aldrich product code: 34923 ) whilst applying a slight pressure on the immersed flowers in order to release the pigment (anthocyanin). The extract was then decanted to remove the solid fragments of the flower petals. The Jamaica flower extract (JFE) was prepared the same day the nano-clays were developed and maintained under refrigeration at $5{ }^{\circ} \mathrm{C}$ in a dark container until further processing, in order to avoid oxidative damages. 


\subsection{Nano-filler formation}

The nano-fillers with added JFE were prepared by mixing $20 \mathrm{~g}$ of each nano-clay used with $50 \mathrm{~mL}$ of JFE. The mixture was then frozen at $-20^{\circ} \mathrm{C}$ for $48 \mathrm{~h}$ after which it was lyophilized at $13.33 \mathrm{~Pa}$ (100 mTorr) and then frozen again at $-50{ }^{\circ} \mathrm{C}$ for $72 \mathrm{~h}$ using a Gland type Vacuum Freeze Dryer, Columbia International, Model FD-1B-50 (Shaan Xi, China) in order to obtain a solvent-free product. Lyophilization also preserves the active compound (anthocyanin) in the JFE and ensures a size of clay particle in the nanometer range. The resultant nano-clays were conditioned in containers with a saturated solution of $\mathrm{NaBr}\left(a_{w}\right.$ $\sim 0.575$ at $25^{\circ} \mathrm{C}$ ) for seven days before preparing the bionanocomposite films in order to maintain controlled and known conditions. During this period the containers were protected from light in a dark room to avoid the photodegradation of the pigment. Six nano-filler - JFE combinations were used and labeled as follows: natural Mnt (NMnt), natural Mnt containing JFE (NMnt + JFE), Mnt modified with dimethyl benzylhydrogenated tallow ammonium (MntMB), Mnt modified with dimethyl benzylhydrogenated tallow ammonium containing JFE (MntMB + JFE), Mnt modified with dimethyl dihydrogenated tallow ammonium (MntMD) and Mnt modified with dimethyl dihydrogenated tallow ammonium containing JFE (MntMD + JFE). These nano-fillers have already been exhaustively characterized by our research group in Gutiérrez, León, et al. (2018).

\subsection{Film formation and extrusion conditions}

Bionanocomposite films were made from native corn starch using a 120:280 (g/g) ratio (glycerol:starch). To evaluate the effects of each filler (NMnt, NMnt + JFE, MntMB, MntMB + JFE, MntMD and MntMD + JFE) on the properties of the resulting films, $16 \mathrm{~g}(4 \% \mathrm{w} / \mathrm{w})$ of each nano-filler was added to the starch content of each film system, maintaining the same glycerol:starch ratio. This percentage was employed based on previous studies carried out by our research group (Gutiérrez \& Alvarez, 2018; Toro-Márquez et al., 2018): percentages greater than $4 \% \mathrm{w} / \mathrm{w}$ can deteriorate the mechanical properties of the developed materials. Each system was pre-blended manually until homogeneous mixtures were obtained. The mixtures were then processed by extrusion in a twin-screw extruder with six heating zones. The temperature profile used was $90 / 100 / 105 / 110 / 110 / 110{ }^{\circ} \mathrm{C}$ with a screw rotation speed of $20 \mathrm{~Hz}$. After processing, the materials obtained from the extruder were allowed to cool to room temperature $\left(25^{\circ} \mathrm{C}\right)$ before being pelletized using an automatic pelletizer (Weinuo Technology Co., Ltd, Jiangsu, China). The pellets ( $90 \mathrm{~g}$ per film system) were then hot-pressed using a hydraulic press at $120^{\circ} \mathrm{C}$ and $1 \times 10^{7} \mathrm{~Pa}$ (100 bar) for $20 \mathrm{~min}$, after which a cooling cycle was applied until they reached a temperature of $30{ }^{\circ} \mathrm{C}$. The seven resulting materials were: thermoplastic starch (TPS), TPS + NMnt, TPS + NMnt + JFE, TPS + MntMB, TPS + MntMB + JFE, TPS + MntMD and TPS + MntMD + JFE. Finally, the prepared films were conditioned under controlled relative humidity $(\sim 57 \%)$ and temperature $\left(25^{\circ} \mathrm{C}\right)$ for one week before characterization.

\subsection{Film characterization}

\subsubsection{Attenuated total reflectance fourier transform infrared (ATR/FTIR) spectroscopy}

The infrared spectra of the film samples were obtained using a Nicolet 6700 FTIR spectrometer (Thermo Scientific Instrument Co., Madison, Wisconsin, USA) with the single reflection horizontal ATR accessory Smart Orbit, and diamond crystal at an incident angle of $45^{\circ}$. FTIR spectra were acquired in the range of $400-4000 \mathrm{~cm}^{-1}$ from 32 coadded scans at $4 \mathrm{~cm}^{-1}$ resolution. The FTIR spectra were used to identify the chemical interactions between the matrices and the natural fillers. Each sample was scanned twice, observing good reproducibility.

\subsubsection{Differential scanning calorimetry (DSC)}

The DSC thermograms were acquired using a DSC Q2000 (Hüllhorst, Germany) to determine the glass transition temperatures $\left(\mathrm{T}_{\mathrm{g}}\right)$ and enthalpies $(\Delta \mathrm{H})$ associated with the amorphous phases of the films under study. The $T_{g}$ was measured as the temperature in the middle of the relaxation range and the $\Delta \mathrm{H}$ as the difference in heat flow. Samples of 6-7 mg each were weighed, placed individually in aluminum pans and hermetically sealed; an empty pan was used as a reference. Initially, samples were heated at a rate of $20^{\circ} \mathrm{C} / \mathrm{min}$ from $30^{\circ} \mathrm{C}$ to $120^{\circ} \mathrm{C}$ under nitrogen atmosphere to remove previous thermal history and moisture (Gutiérrez, Herniou-Julien, et al., 2018). They were then cooled down to $-90^{\circ} \mathrm{C}$ using an intracooler (TA Refrigerated Cooling Systems 90 - RCS90, Hüllhorst, Germany) and re-heated to $250{ }^{\circ} \mathrm{C}$ at a heating rate of $10{ }^{\circ} \mathrm{C} / \mathrm{min}$. Two samples of each film system were tested to ensure repeatability. All the thermograms shown refer to the second heating.

\subsubsection{Swelling (SW)}

The percent SW of the films was determined according to the method described by Liu et al. (2017). Samples of each film type were initially cut into $11 \mathrm{~mm}$ diameter discs $\left(\emptyset_{i}\right)$. The discs were dried and immersed in containers with $20 \mathrm{~mL}$ distilled water. The containers were then sealed and maintained at $25{ }^{\circ} \mathrm{C}$ for $24 \mathrm{~h}$. Changes in the disc diameters $\left(\emptyset_{f}\right)$ of the samples were recorded with an 8.1 mega-pixel Cybershot Sony camera, model DSC-H3 (Japan). At least three samples of each film system were tested to ensure good reproducibility and the SW (\%) \pm standard deviation (SD) was reported. SW was calculated using [Eq. (1)]:

$S W(\%)=\left(\emptyset_{f}-\emptyset_{i}\right) * \emptyset_{i}^{-1} * 100$

\subsubsection{Moisture content (MC)}

The MC of the different film systems was calculated using the methodology described by AOAC (1990) and the following equation:

$M C(\%)=\frac{m_{w}-m_{d}}{m_{w}} \times 100$

where $m_{w}$ is the wet mass and $m_{d}$ the dry mass of each film system. The dry mass of the films was determined by cutting samples of each system into $2 \mathrm{~cm} \times 2 \mathrm{~cm}$ pieces, heating them in an oven at $105^{\circ} \mathrm{C}$ for $24 \mathrm{~h}$, and then weighting each one with an analytical balance (Denver Instrument APX-200). Analyses were performed in triplicate and the MC (\%) \pm SD reported.

\subsubsection{Surface moisture (SM)}

A Moisture Analyzer, Model MA150 (Goettingen, Germany), was used to estimate the SM content of the films. Square $(2 \mathrm{~cm} \times 2 \mathrm{~cm})$ samples were dried at $105^{\circ} \mathrm{C}$ for $120 \mathrm{~s}$. Measurements were conducted in triplicate for each film and the results reported as the average SM (\%) \pm SD.

\subsubsection{Water contact angle (WCA)}

The water contact angles (WCAs, $\theta$ ) of the thermo-compressed films were determined by carefully placing one drop of distilled water $(2 \mu \mathrm{L})$ onto the thermo-compressed film surfaces using a syringe (KDL Corp., Shanghai, China) and then quickly measuring the WCAs before swelling commenced with a Ramé-Hart instrument (contact angle goniometer) model 100-25-4 (Mountain Lakes, New Jersey, USA) equipped with drop image advanced software at $0.0001^{\circ}$ precision, under ambient conditions, i.e. $25^{\circ} \mathrm{C}$ air temperature. The WCAs were then calculated from the intersection of the liquid-solid interface (drop of water-surface of the film) and the liquid-vapor interface (tangent to the boundary of the drop) (Gutiérrez \& González, 2017). The WCAs were expressed as the average of 12 measurements per film \pm SD. 


\subsubsection{Surface energy measurements}

The bromonaphthalene (BCA) and di-iodomethane (DCA) contact angles $(\theta)$ were measured using a Ramé-Hart instrument model 100-254 equipped with drop image advanced software. The contact angles formed between the liquid-solid interface and the liquid-vapor interface (tangent to the surface of the drop) were determined by placing a $2 \mu \mathrm{L}$ drop of bromonaphthalene (Sigma Aldrich, 97\%, CAS: 90-11-9) or diiodomethane (Sigma Aldrich, 99\%, CAS: 15.842-9) onto the film surface. Experiments were carried out at $25^{\circ} \mathrm{C}$. At least 12 measurements per sample were done and the resulting BCAs and DCAs used to calculate and analyze the total surface energy of each sample.

The total surface energy of each sample and their polar and dispersive components were then calculated using the equation proposed by Owens (1970):

$\gamma_{L} \frac{(1+\cos \theta)}{2}=\left(\gamma_{S}^{d} \gamma_{L}^{d}\right)^{1 / 2}+\left(\gamma_{S}^{p} \gamma_{L}^{p}\right)^{1 / 2}$

where $\gamma^{\mathrm{d}}$ and $\gamma^{\mathrm{p}}$ are the dispersive and polar components of surface free energy, respectively. The subscript $S$ refers to the solid, and $L$ to the liquid, and $\theta$ is the contact angle (Gutiérrez \& González, 2017). The total surface energy, $\gamma_{s}$, can then be estimated by [Eq. (4)]:

$\gamma_{S}=\gamma_{S}^{P}+\gamma_{S}^{d}$

The surface energy components of the probe liquids used for the contact angle measurements are listed in Table 1 (Cyras, Manfredi, TonThat, \& Vázquez, 2008).

\subsubsection{Scanning electron microscopy (SEM)}

The surfaces of the thermo-compressed films were analyzed using a JEOL JSM-6460 LV scanning electron microscope. For the analyses, films were mounted on bronze stubs and sputter-coated (Sputter coater SPI Module, Santa Clara, CA, USA) with a thin layer of gold for $35 \mathrm{~s}$. They were then observed at an accelerating voltage of $15 \mathrm{kV}$ and magnification $1 \mathrm{k} \times$.

\subsubsection{Biodegradability in vegetable compost}

The biodegradability of the films developed was determined at 2, 7 , 14, 21, 30 and 90 days using the protocol described by Gutiérrez (2018b). Percent biodegradability (\%) was then calculated as follows:

Biodegradability $(\%)=\left(m_{i}-m_{f}\right) * m_{i}^{-1} * 100$

where $m_{i}$ is the initial mass on dry basis of each film measured before the test, and $m_{f}$ the final dry mass of each film after the test. It is worth noting that the organic matter from the vegetable compost (soil) adhered to the samples was removed by air flow under pressure before determining the final dry mass of the samples. Assays were carried out at $25^{\circ} \mathrm{C}$ and controlled humidity conditions (70-80\%). The analyses were performed in triplicate, and the biodegradability (\%) \pm SD reported.

2.4.10. Variation in the growth of the primary root of lettuce (Lactuca sativa) seedlings as an ecotoxicity bioassay

The films were dried in an oven at $105^{\circ} \mathrm{C}$ for $48 \mathrm{~h}$ and then pulverized in a grinder to obtain a fine powder. Lettuce (Lactuca sativa)

Table 1

Total surface energy $\left(\gamma_{l}\right)$ and their polar $\left(\gamma_{l}^{P}\right)$ and dispersive $\left(\gamma_{l}^{d}\right)$ components for the liquids used (bromonaphthalene and di-iodomethane) for the calculation of total surface energy $\left(\gamma_{s}\right)$, and polar $\left(\gamma_{s}^{P}\right)$ and dispersive $\left(\gamma_{s}^{d}\right)$ components of the different nanocomposite films.

\begin{tabular}{lll}
\hline$(\mathrm{mN} / \mathrm{m})$ & Bromonaphthalene & Di-iodomethane \\
\hline$\gamma_{l}$ & 44.4 & 50.8 \\
$\gamma_{l}^{P}$ & 0.0 & 2.3 \\
$\gamma_{l}^{d}$ & 44.4 & 48.5 \\
\hline
\end{tabular}

seeds were purchased from Cooperativa de Agricultores Mar del Plata (Mar del Plata, Argentina). The seeds were surface-sterilized in $30 \%$ commercial bleach and $0.2 \%$ Tween 20 for $10 \mathrm{~min}$ and rinsed three times with sterile water. They were then plated on $0.8 \%$ Agar- $\mathrm{H}_{2} \mathrm{O}$ and placed in a growth chamber at $25^{\circ} \mathrm{C}$ with $16 \mathrm{~h}$ light photoperiod. Four days post-germination the seedlings were transferred to agar plates containing either $\mathrm{H}_{2} \mathrm{O}$ or one of three different concentrations of each powdered film system $(1,10$ and $100 \mu \mathrm{g} / \mathrm{mL}$ ). After 4 days, the seedlings were photographed, and the lengths of the primary roots measured using ImageJ image-analysis software (USA National Institute of Health). The values shown are the mean values \pm SD from three independent experiments. Data are expressed as percentages of the average length of the primary roots of the seedlings, using the average length of the primary roots of the seedlings supplemented with the TPS film as a reference (control) film system (film without natural nanofillers).

\subsection{Statistical analysis}

Analyses of variance (ANOVA), using OriginPro 8 software (Version 8.5, Northampton, USA) were employed to analyze the data and the results are shown as mean values \pm SD. Differences between the mean values of the measured properties were compared using a multiplerange Tukey's test. A significance level of 0.05 was used.

\section{Results and discussion}

\subsection{Attenuated total reflectance fourier transform infrared (ATR/FTIR) spectroscopy}

The FTIR spectroscopy was used to investigate the hydrogen $(\mathrm{H})$ bonding interactions between the matrix, nano-fillers and plasticizer. Fig. 1A shows the FTIR spectra of the bionanocomposite films developed. All the spectra showed common bands at 3280, 2925, 2880, 1650, 1365, 1008 and $927 \mathrm{~cm}^{-1}$. The first of these, $3280 \mathrm{~cm}^{-1}$, corresponds to the stretching vibration frequency of the $\mathrm{OH}$ groups present in the hydroxyls in the glucose rings of the starch, the glycerol, and the adsorbed and free water molecules (Bourtoom \& Chinnan, 2008; Dang \& Yoksan, 2015; Shi et al., 2007). The peaks at 2925 and $2880 \mathrm{~cm}^{-1}$ are due to the antisymmetric and symmetric stretching frequencies of the $\mathrm{C}-\mathrm{H}$ bonds, while the bands at 1650 and $1365 \mathrm{~cm}^{-1}$ correspond to the bending and stretching vibration frequencies of the $\mathrm{O}-\mathrm{H}$ groups in the water bonded to the matrix (Dang \& Yoksan, 2015). The bands localized at $1008 \mathrm{~cm}^{-1}$ and $927 \mathrm{~cm}^{-1}$ relate to the stretching frequencies of the $\mathrm{C}-\mathrm{O}$ bonds in the $\mathrm{C}-\mathrm{O}-\mathrm{C}$ chains and the stretching vibration of the pyranose ring, respectively (Dang \& Yoksan, 2015; Lopez et al., 2014; Mendes et al., 2016). Although the bands mentioned above occurred at the same frequencies in all the samples tested, differences were observed in the absorbance of the peaks appearing at 3280 and $1365 \mathrm{~cm}^{-1}$, both of which can be attributed to the $\mathrm{O}-\mathrm{H}$ stretching vibrations. A decrease in their absorbance signifies that there are fewer of these groups present (Gutiérrez \& Alvarez, 2017). The ratio between the absorbance at $3300 \mathrm{~cm}^{-1}\left(\mathrm{~A}_{3300}\right)$ and $1150 \mathrm{~cm}^{-1}\left(\mathrm{~A}_{1150}\right)$ $\left(A_{3300} / A_{1150}\right.$ ratio) was used by Shi et al. (2007) to compare the amount of available $\mathrm{OH}$ groups in these types of systems (Fig. 1B and C). In this study the $A_{3300} / A_{1150}$ ratios of the different film systems were in the following ascending order: TPS + NMnt + JFE $(4.31)<$ TPS + MntMB + JFE (4.32) $<$ TPS + MntMB (4.67) $<$ TPS (4.70) $<$ TPS + MntMD + JFE $(4.76)<$ TPS + MntMD (4.98) $<$ TPS + NMnt (5.10). These results suggest that the films prepared with the nano-fillers containing the Jamaica flower extract (JFE - rich in anthocyanins/polyphenol) have fewer available $\mathrm{OH}$ groups within their structure than their analogous films containing the nano-fillers but without JFE. This is possibly because the JFE (polar compound) forms compensatory H-bonding interactions with the thermoplastic starch (TPS) matrix and glycerol, thus reducing the number of available $\mathrm{OH}$ groups. The TPS $+\mathrm{NMnt}+\mathrm{JFE}$ film had the lowest number of available $\mathrm{OH}$ groups. According to Gutiérrez, León, et al. 
A

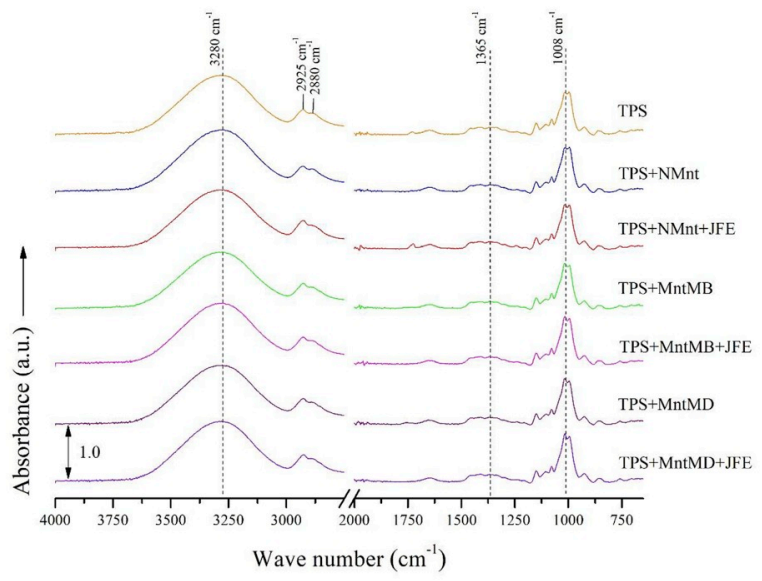

B

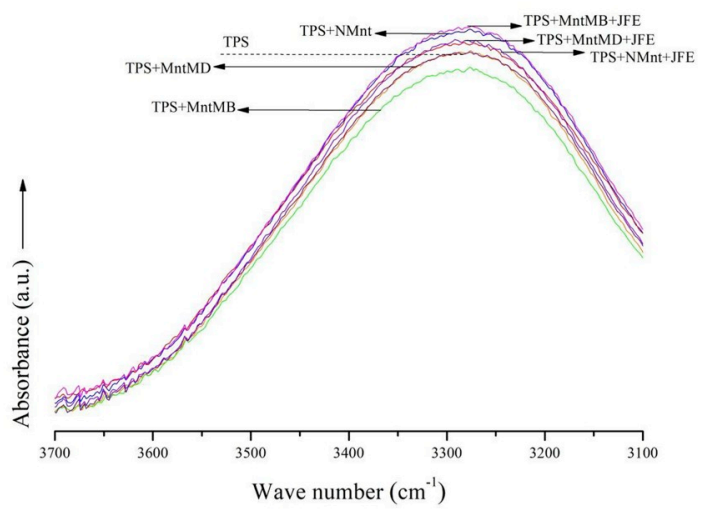

C

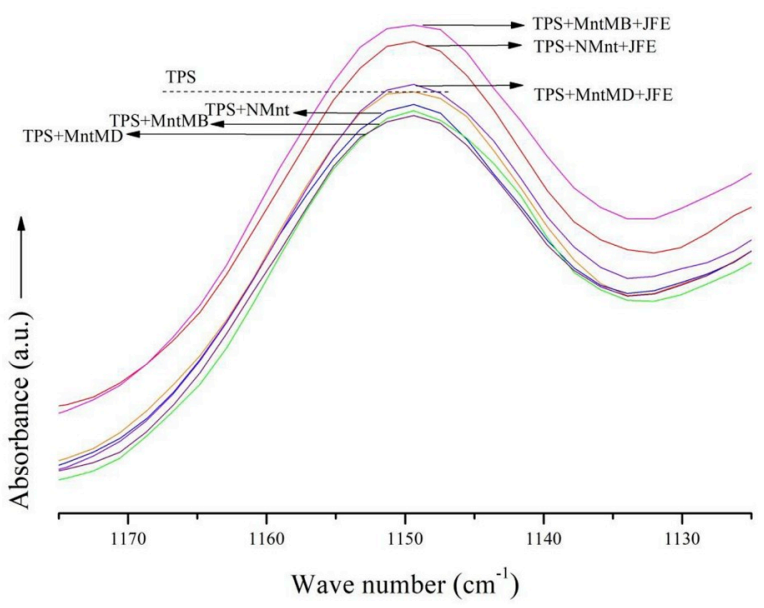

Fig. 1. Panel A- FTIR spectra of the different films studied in all the absorption range. Panel B- FTIR spectra in the absorption range corresponding to C-O group (OH stretching) of the different films studied. Panel C- FTIR spectra in the absorption range corresponding to $\mathrm{C}=\mathrm{O}$ group $\left(1175-1125 \mathrm{~cm}^{-1}\right)$. Film systems: thermoplastic starch (TPS), TPS + natural montmorillonite (TPS + NMnt), TPS + natural montmorillonite containing Jamaica flower extract (TPS + NMnt + JFE), TPS + montmorillonite modified with dimethyl benzylhydrogenated tallow ammonium (TPS + MntMB), TPS + montmorillonite modified with dimethyl benzylhydrogenated tallow ammonium containing Jamaica flower extract (TPS + MntMB + JFE), TPS + montmorillonite modified with dimethyl dihydrogenated tallow ammonium (TPS + MntMD) and TPS + montmorillonite modified with dimethyl dihydrogenated tallow ammonium containing Jamaica flower extract (TPS + MntMD + JFE).
(2018) the surface chemical interactions between the NMnt nano-clay and the JFE (the JFE was not found within the interlayer spacing of this nanoclay) stabilize the JFE. It is thus probable that the JFE on the surface of the natural nano-filler (NMnt + JFE) formed stronger H-bonding interactions with the TPS matrix than the JFE contained within their interlayer spacings of the organo-modified clay nano-fillers. This could be why the polar extract (JFE) stabilized on the outer layers of the natural nano-clay (NMnt + JFE) showed the greatest compatibility with the TPS matrix, thus reducing the number of the available $\mathrm{OH}$ groups (polar sites - Lewis sites). The higher number of available $\mathrm{OH}$ groups in the films containing organo-modified nano-fillers, where the JFE was contained within their interlayer spacings, was possibly because, since the JFE was confined to very small spaces between the interlayers of the nano-clays, the starch chains failed to efficiently enter into the nano-clay layers and were thus unable to successfully establish compensatory H-bonding interactions with the JFE.

Gutiérrez, León, et al. (2018) also reported that the MntMD nanofiller had a higher content of the modifying agent in the interlayer spacing than the other organo-modified (MntMB) nano-filler used. According to these authors, this limits the amount of JFE that can be nanopacked within the interlayer spacings in the former. This explains why the TPS + MntMB + JFE film had a lower number of available $\mathrm{OH}$ groups than the TPS + MntMD + JFE film. To summarize, so far we have established that: 1) the stabilization of the polar extract (JFE) on the surface of the nano-fillers results in stronger compensatory $\mathrm{H}$ bonding interactions between the nano-filler and the TPS matrix or glycerol than these same compensatory H-bonding interactions when the polar extract (JFE) is nano-packed within the interlayer spacings of the nano-clays, and 2) nano-fillers that can nano-pack greater amounts of the polar extract (JFE) show stronger H-bonding interactions between the TPS matrix and the nano-filler containing the polar extract.

Regarding the films containing the organo-modified nano-fillers without nano-packed JFE (TPS + MntMB - 4.67 and TPS + MntMD 4.98), it can be established by means of the results reported by Gutiérrez, León, et al. (2018) that those nano-fillers containing higher content of the organo-modifying agent within the layers of the nanofiller limit the nano-clay-TPS interactions, leading to a rise in the number of available $\mathrm{OH}$ groups.

Thus, the first conclusion reached by this study (which will be confirmed with the results given in later sections) is that a greater steric hindrance that either reduces the amount of polar extract within the nano-filler or limits its H-bonding interactions with the TPS matrix/ glycerol (plasticizer) leads to an increase in the number of available $\mathrm{OH}$ groups. This increase in the number of available $\mathrm{OH}$ groups also occurs if the amount of organo-modifying material present obstructs interactions between the nano-clay and the TPS matrix.

\subsection{Differential scanning calorimetry (DSC)}

It is well known that the glass transition temperature $\left(\mathrm{T}_{\mathrm{g}}\right)$ is associated with slight enthalpy changes that enable the study of the amorphous phase of a polymer, while the melting temperature $\left(\mathrm{T}_{\mathrm{m}}\right)$ is related to endothermic melting peaks corresponding to the crystalline phase of polymeric materials (González Seligra, Eloy Moura, Famá, Druzian Janice, \& Goyanes, 2016). According to Gutiérrez, HerniouJulien, et al. (2018) the $T_{m}$ in TPS-based films can be associated with the different types of resistant starch (RS). The films developed in this study were all "non-retrogradable", since no melting peaks were observed for any of the film systems evaluated (Fig. 2A). It should be noted that retrograde starch is classified as RS type 3 (RS3). As regards, the amorphous phase of the films developed only the TPS and TPS + NMnt + JFE film systems gave values of $\mathrm{T}_{g}$ (TPS $-59.3^{\circ} \mathrm{C}$, Fig. $2 \mathrm{~B}$ and TPS + NMnt + JFE $-60.5{ }^{\circ} \mathrm{C}$, Fig. $2 \mathrm{C}$ ). The $\mathrm{T}_{\mathrm{g}}$ can be measured only when the macromolecules of the polymer show some mobility, and an increase in its value is caused by steric impediments to this mobility (Gutiérrez et al., 2016). The lack of a measureable $\mathrm{T}_{\mathrm{g}}$ in all 

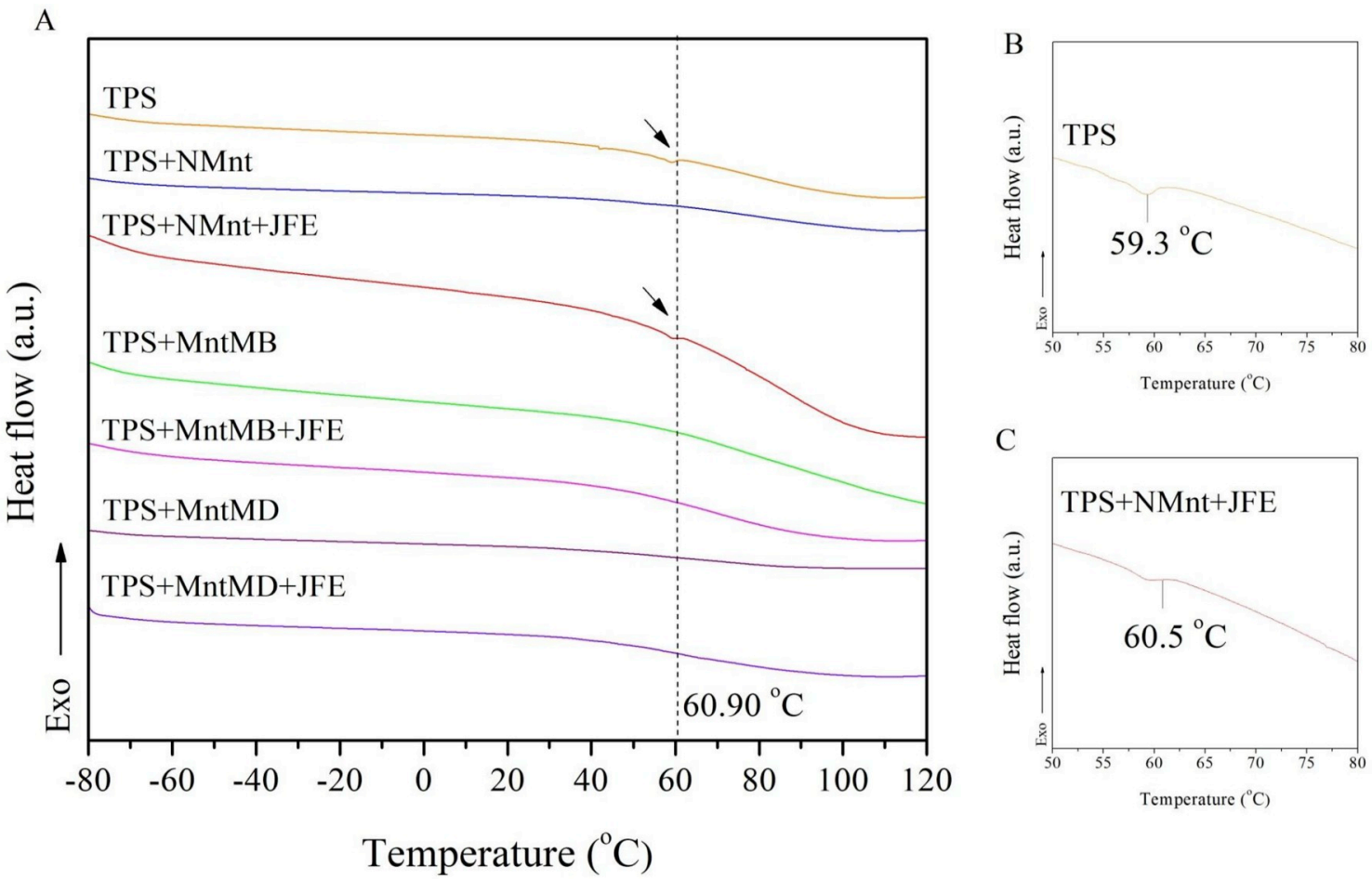

Fig. 2. Heating thermograms of the films based on: thermoplastic starch (TPS), TPS + natural montmorillonite (TPS + NMnt), TPS + natural montmorillonite containing Jamaica flower extract (TPS + NMnt + JFE), TPS + montmorillonite modified with dimethyl benzylhydrogenated tallow ammonium (TPS + MntMB), TPS + montmorillonite modified with dimethyl benzylhydrogenated tallow ammonium containing Jamaica flower extract (TPS + MntMB + JFE), TPS + montmorillonite modified with dimethyl dihydrogenated tallow ammonium (TPS + MntMD) and TPS + montmorillonite modified with dimethyl dihydrogenated tallow ammonium containing Jamaica flower extract (TPS + MntMD + JFE).

Table 2

Swelling $(S W)$, moisture content $(M C)$, surface moisture $(S M)$ and bromonaphthalene $(B C A)$ and di-iodomethane $(D C A)$ contact angles of the different films.

\begin{tabular}{|c|c|c|c|c|c|c|c|}
\hline Parameter & TPS & TPS + NMnt & TPS + NMnt + JFE & TPS + MntMB & $\mathrm{TPS}+\mathrm{MntMB}+\mathrm{JFE}$ & TPS + MntMD & TPS + MntMD + JFE \\
\hline$M C(\%)$ & $21.3 \pm 0.7^{\mathrm{b}, \mathrm{c}, \mathrm{d}}$ & $22 \pm 1^{\mathrm{b}, \mathrm{d}, \mathrm{e}}$ & $16.0 \pm 0.6^{\mathrm{a}}$ & $20 \pm 2^{\mathrm{b}}$ & $18.7 \pm 0.6^{\mathrm{b}}$ & $22 \pm 1^{\mathrm{b}, \mathrm{f}}$ & $20.6 \pm 0.4^{\mathrm{b}, \mathrm{c}}$ \\
\hline$S M(\%)$ & $4.1 \pm 0.8^{\mathrm{a}, \mathrm{b}}$ & $1.8 \pm 0.2^{\mathrm{a}}$ & $2.3 \pm 0.7^{\mathrm{a}}$ & $1.8 \pm 0.3^{\mathrm{a}}$ & $4 \pm 2^{\mathrm{a}}$ & $3.2 \pm 0.3^{\mathrm{a}, \mathrm{b}}$ & $2.0 \pm 0.6^{\mathrm{a}}$ \\
\hline$D C A\left({ }^{\circ}\right)$ & $43.7 \pm 0.9^{\mathrm{b}, \mathrm{c}, \mathrm{d}}$ & $41 \pm 2^{\mathrm{a}, \mathrm{b}}$ & $34 \pm 2^{\mathrm{a}}$ & $45.6 \pm 0.9^{\mathrm{e}}$ & $43.3 \pm 0.5^{\mathrm{b}, \mathrm{c}}$ & $46 \pm 1^{\mathrm{e}}$ & $38 \pm 3^{\mathrm{a}}$ \\
\hline
\end{tabular}

Equal letters in the same row indicate no statistically significant differences ( $\mathrm{p} \leq 0.05)$. Film systems: thermoplastic starch (TPS), TPS + natural montmorillonite (TPS + NMnt), TPS + natural montmorillonite containing Jamaica flower extract (TPS + NMnt + JFE), TPS + montmorillonite modified with dimethyl benzylhydrogenated tallow ammonium (TPS + MntMB), TPS + montmorillonite modified with dimethyl benzylhydrogenated tallow ammonium containing Jamaica flower extract (TPS + MntMB + JFE), TPS + montmorillonite modified with dimethyl dihydrogenated tallow ammonium (TPS + MntMD) and TPS + montmorillonite modified with dimethyl dihydrogenated tallow ammonium containing Jamaica flower extract (TPS + MntMD + JFE).

the films with the added nano-fillers, except for the TPS + NMnt + JFE film, could thus reveal restrictions to the mobility of the TPS chains. It is also worth noting that even though the TPS + NMnt + JFE film did give a $T_{g}$ value $\left(60.5^{\circ} \mathrm{C}\right)$, this was greater than the $T_{g}$ value recorded for the TPS film without the nano-fillers, thus confirming that the presence of the nano-fillers restricted the mobility of the TPS chains. Thus, the $\mathrm{NMnt}+$ JFE nano-filler was the only nano-filler tested that enabled us to satisfactorily reduce the number of available $\mathrm{OH}$ groups without completely immobilizing the TPS chains (mobile TPS chains are necessary to produce plastic materials). Nevertheless, it is worth noting that the non-measurement of $\mathrm{T}_{\mathrm{g}}$ by DSC in this study does not necessarily mean the non-existence of $\mathrm{T}_{\mathrm{g}}$ values, since it could be determined by other techniques such as Dynamic Mechanical Thermal Analysis (DMTA).

\subsection{Swelling (SW)}

The SW values (Table 2 - Appendix C) show that the TPS film had the lowest SW value (approx. 13\%). However, no statistically significant differences ( $p \geq 0.05$ ) were observed between TPS film and the films containing the nano-fillers with JFE (TPS + NMnt + JFE, TPS + MntMB + JFE and TPS + MntMD + JFE). These results suggest that clay nano-fillers tend to increase the SW properties of bionanocomposite film systems. This means that the physical integrity of the films could collapse when used as packaging materials for foods with high water activity thus limiting their application in this field. It should be noted that the bionanocomposite films made from the JFE-containing nano-fillers swelled up less $(\mathrm{p} \leq 0.05)$ when placed in an aqueous medium than their analogous films containing the nano-fillers but without the JFE. It is probable that the strong compensatory $\mathrm{H}$ bonding interactions found between the TPS matrix and the nano-fillers containing the polar extract (JFE) prevented the water molecules in the medium from interacting efficiently with the TPS matrix. Thus, stronger compensatory H-bonding interactions between the constituents of the TPS-based bionanocomposite films lead to reduced SW. This fits well with the FTIR spectra results (see section 3.1). 


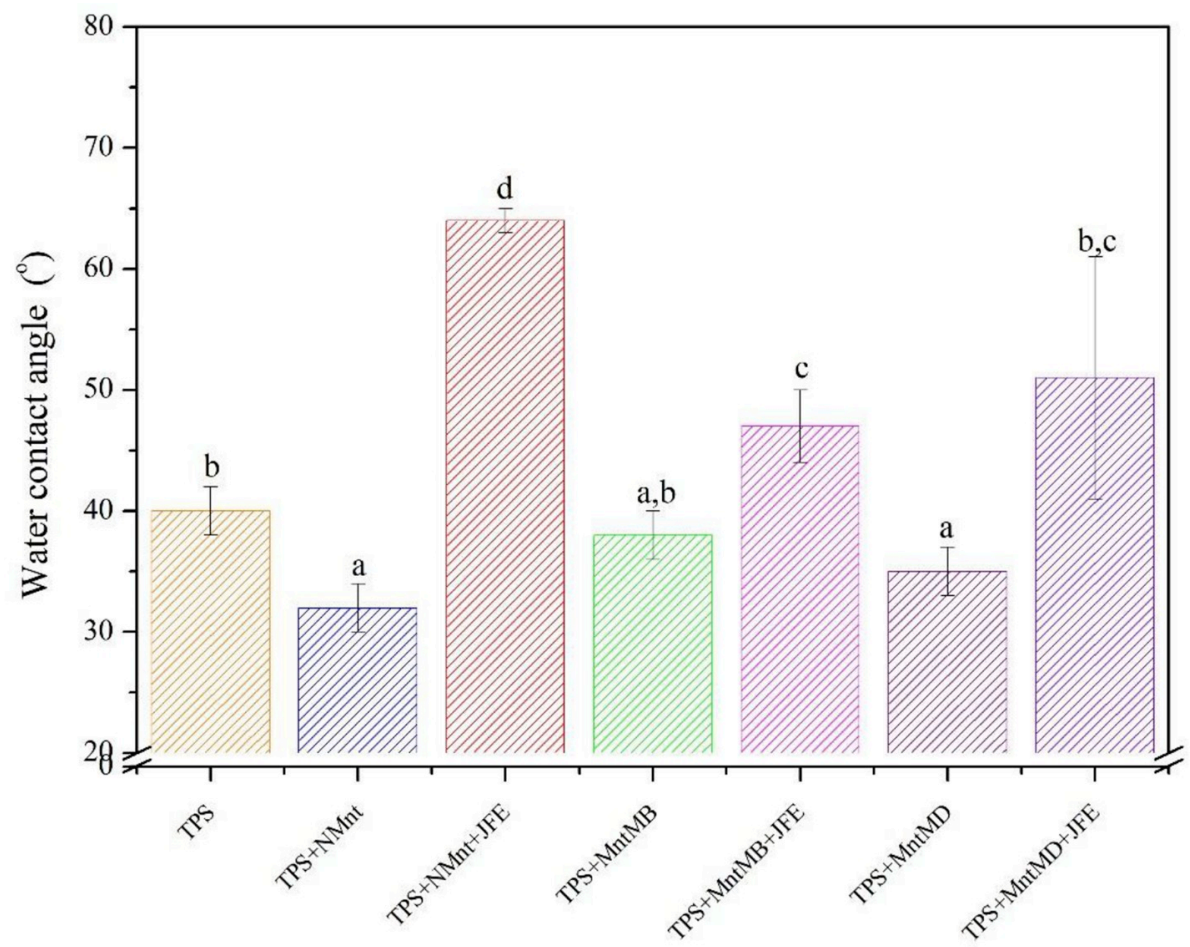

Fig. 3. Water contact angle (WCA) values of the films based on: thermoplastic starch (TPS), TPS + natural montmorillonite (TPS + NMnt), TPS + natural montmorillonite containing Jamaica flower extract (TPS + NMnt + JFE), TPS + montmorillonite modified with dimethyl benzylhydrogenated tallow ammonium (TPS + MntMB), TPS + montmorillonite modified with dimethyl benzylhydrogenated tallow ammonium containing Jamaica flower extract (TPS + MntMB + JFE), TPS + montmorillonite modified with dimethyl dihydrogenated tallow ammonium (TPS + MntMD) and TPS + montmorillonite modified with dimethyl dihydrogenated tallow ammonium containing Jamaica flower extract (TPS + MntMD + JFE). Equal letters in the columns indicate no statistically significant differences $(\mathrm{p} \leq 0.05)$.

\subsection{Moisture content (MC) \& surface moisture (SM)}

The MC values (Table 2) showed that the driest material was the TPS + NMnt + JFE film. This agrees with the fact that this film system had the lowest number of available $\mathrm{OH}$ groups (polar sites - Lewis sites) (see section 3.1). Thus, lower numbers of available $\mathrm{OH}$ results in materials with lower MC, since there are fewer polar sites to absorb moisture from the environment.

The film systems with the JFE-containing nano-fillers tended to have a lower MC than their analogous film systems containing nanofillers but without JFE. These results confirm that more and stronger compensatory H-bonding interactions between the TPS matrix and the nano-fillers containing the polar extract (JFE) reduce the water sensitivity of the bionanocomposite film systems. However, statistically significant differences ( $\mathrm{p} \leq 0.05$ ) were only observed between the TPS + NMnt and TPS + NMnt + JFE film. No differences were found between the MCs of the films prepared from the organo-modified nanoclays (TPS + MntMB; TPS + MntMD) and the natural nano-clay (TPS + NMnt).

The MC and the SM may not necessarily show the same trend since the SM provides information about the hydrophilicity of the surface, whereas MC is a measure of the water susceptibility of the material in general. For example, the molecular rearrangement of the TPS chains may be preferentially ordered, i.e. a TPS film may be water sensitive, but its surface may tend to be hydrophobic if the polar sites (where the available $\mathrm{OH}$ groups are found) are oriented towards the interior of the material, and the apolar sites are oriented towards the surface (Gutiérrez \& Alvarez, 2018). Similarly, stronger H-bonding interactions below the surface can lead to either a drier surface or a hydrophilic surface (Gutiérrez, Ollier, \& Alvarez, 2018). The SM values (Table 2) were, as expected, lower than the MC of the films. The films with nanofillers tended to have a lower SM, i.e. a lower water surface sensitivity than the TPS film. Nonetheless, no statistically significant differences ( $\mathrm{p} \geq 0.05$ ) were determined between the TPS film and the TPS + MntMB + JFE and TPS + MntMD films. However, the TPS + MntMD + JFE film did have a lower SM value $(2.0 \%)$ than its analogous film containing the nano-filler but without JFE (TPS + MntMD, 3.2\%). This possibly occurred because the
TPS + MntMD + JFE had stronger compensatory H-bonding interactions below the surface of the material, together with fewer Lewis sites on the surface. This behavior was not observed for the other analogous pairs of films.

3.5. Water contact angle (WCA), surface energy measurements \& scanning electron microscopy (SEM)

An increase in WCA is often associated with an increase in the hydrophobic character of the surfaces of biopolymer films (Vogler, 1998). Here, the WCA values of all the bionanocomposite films containing the nano-fillers plus JFE (Fig. 3) were statistically higher ( $p \leq 0.05$ ) than their analogous bionanocomposite films containing the nano-fillers but without JFE. These results together with the previous discussion (see section 3.4) confirm that the addition of the JFE results in the formation of stronger compensatory H-bonding interactions between the TPS matrix and the JFE-packaged nano-fillers, resulting in bionanocomposite films with fewer available $\mathrm{OH}$ groups. A negative correlation was also observed between the number of available $\mathrm{OH}$ groups and the WCA values. Thus, bionanocomposite films containing fewer available $\mathrm{OH}$ groups showed higher WCA values, with the TPS + NMnt + JFE film having the highest WCA and the lowest number of available $\mathrm{OH}$ groups. This may be because, since the TPS chains of this film system showed some mobility (see DSC results, section 3.2), they could have been reorganized such that the $\mathrm{OH}$ groups were oriented towards the inside of the material and the hydrophobic ends were directed towards the surface. The highest WCA value, recorded for the TPS + NMnt + JFE film, could also be due to the presence of the polar extract (JFE), which confers it with fewer steric impediments to the establishment of compensatory H-bonding interactions between the TPS chains and the NMnt + JFE nano-filler. As a result, the number of Lewis sites on the surface of the material are reduced, and the WCA increases. In contrast, the TPS + NMnt film showed the highest number of available $\mathrm{OH}$ groups, and the lowest WCA values.

The surface properties of bionanocomposite films have been poorly studied; however, their analysis could be interesting for the development of anti-quorum sensing films (Gutiérrez, 2018c; Gutiérrez, Ollier et al., 2018), or active films that can immobilize enzymes, such as 
lactase, for the development of materials that reduce the production of lactose in dairy products, for example milk. This means that foods low in lactose can be obtained during storage and consumed by people on special diet regimes such as the lactose intolerant. This and other innovations are currently being actively researched, and in fact the development of modified foods through the use of active packaging with

A

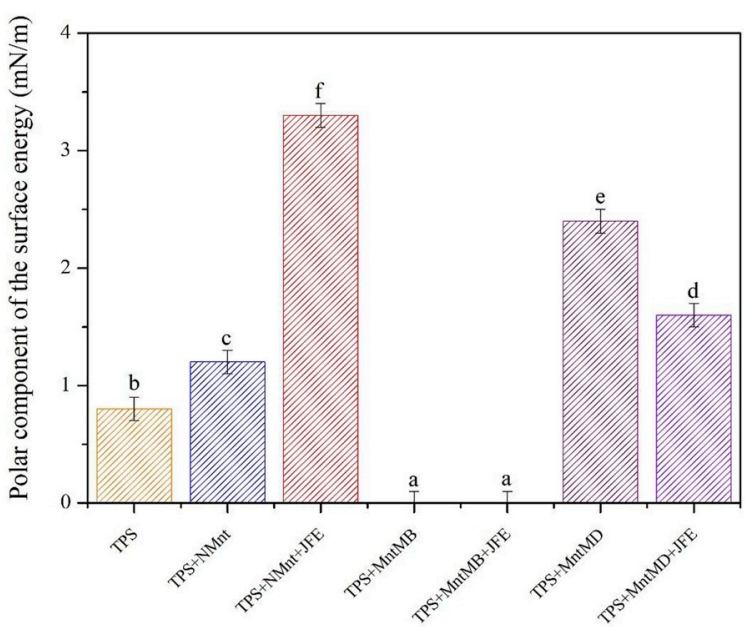

B

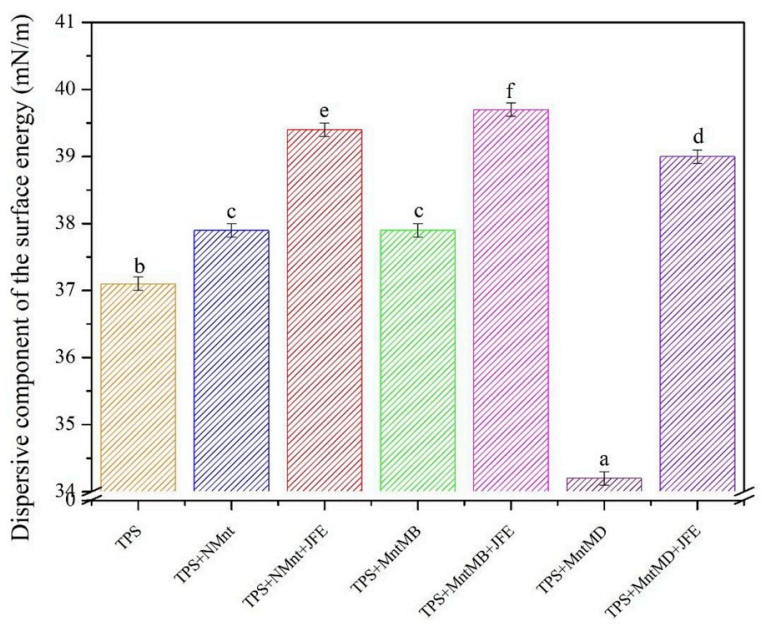

C

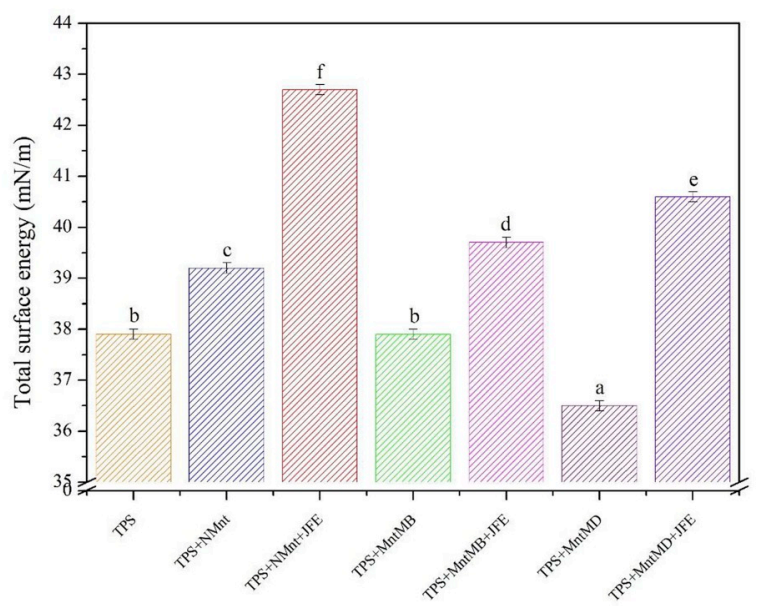

Fig. 4. Panel A- Values of the polar component $\left(\gamma_{s}^{P}\right)$ of the surface energy. Panel B- Values of the dispersive component $\left(\gamma_{s}^{d}\right)$ of the surface energy. Panel C- Values of total surface energy $\left(\gamma_{s}\right)$ of the different films studied. Film systems: thermoplastic starch (TPS), TPS + natural montmorillonite (TPS + NMnt), TPS + natural montmorillonite containing Jamaica flower extract (TPS + NMnt + JFE), TPS + montmorillonite modified with dimethyl benzylhydrogenated tallow ammonium (TPS + MntMB), TPS + montmorillonite modified with dimethyl benzylhydrogenated tallow ammonium containing Jamaica flower extract (TPS + MntMB + JFE), TPS + montmorillonite modified with dimethyl dihydrogenated tallow ammonium (TPS + MntMD) and TPS + montmorillonite modified with dimethyl dihydrogenated tallow ammonium containing Jamaica flower extract (TPS + MntMD + JFE). Equal letters in the columns indicate no statistically significant differences ( $\mathrm{p} \leq 0.05)$.

modified surfaces is in full technological boom (Gutiérrez, Ollier et al., 2018). To investigate more about the surface properties of the developed bionanocomposite films, total surface energy $\left(\gamma_{s}\right)$, and its polar $\left(\gamma_{s}^{P}\right)$ and dispersive $\left(\gamma_{s}^{d}\right)$ components were calculated using: 1) the constants associated with the two solvents: bromonaphthalene and diiodomethane (Table 1), 2) the values of the contact angles generated with the two different solvents (Table 2), and 3) the equations proposed by Owens (1970).

Frequently, films manufactured from biopolymers show bipolar behavior, i.e. both the polar and the dispersive components contribute to the total surface energy of these materials (Aphibanthammakit, Nigen, Gaucel, Sanchez, \& Chalier, 2018). However, in this study the TPS + MntMB and TPS + MntMB + JFE films did not behave in this way, since they did not have a polar component (Fig. 4A). In contrast, the polar component values of the bionanocomposite films containing the other nano-fillers used were higher than that of the TPS film.

The values of the dispersive component of the surface energy of the developed films (Fig. 4B), i.e. the component associated with the apolar sites on the surface of the materials, were at least 8.5 times higher than those of the polar component. In addition, the energy values of the dispersive component in the film systems containing the JFE-packaging nanofiller were higher than those containing the nano-filler without JFE. These results suggest that the reduction in the number of available $\mathrm{OH}$ groups, due to stronger H-bonding interactions between the film constituents, increased the values of the dispersive component of surface energy. The higher the values of the energy of the dispersive component, the more energy a polar substance such as water needs to collapse its structure and moisten a surface. In general, this is in line with the results from the WCA measurements, i.e. higher WCA values are a product of the higher values of the dispersive component of the surface energy. These, in turn, depend on efficient H-bonding interactions that occur between the constituents of the bionanocomposite films below the surface of the materials, which lead to a reduction in the number of available $\mathrm{OH}$ groups. It is worth noting, however, that the comparison between the TPS and TPS + NMnt films did not adjust well to this analysis.

The total surface energy values of the bionanocomposite films varied from 36.5 to $42.7 \mathrm{mN} / \mathrm{m}$ (Fig. 4C). Similar results of total surface energy (between 35 and $45 \mathrm{mN} / \mathrm{m}$ ) were reported by Cyras et al. (2008) for bionanocomposite films containing between 1 and $5 \%$ NMnt. In general, there was a positive relationship between the WCA results and the surface energy values, except again when the TPS and TPS + NMnt films were compared with each other. Gutiérrez and González (2017) observed an increase in the WCA values of films made from plantain flour cross-linked with aloe vera gel, which they linked to the higher values of total surface energy also found for these films.

The SEM images of the bionanocomposite films (Fig. 5) showed that the films containing the JFE-packaged nano-fillers had a more irregular morphology than their JFE-free analogous films, which had smoother surfaces. According to Wenzel (1936) a greater surface roughness indicates the presence of physical obstacles that prevent the collapse of water drops, thus increasing the WCA values. This fits well with the results reported here. 

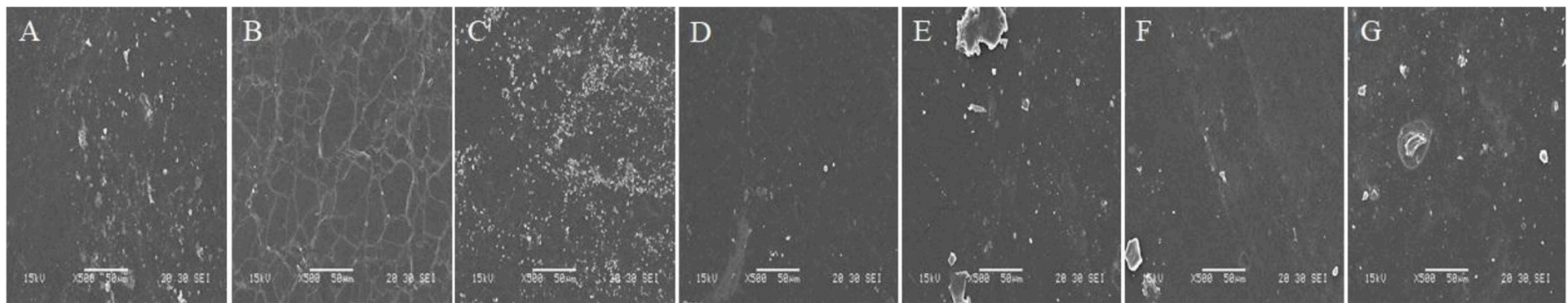

Fig. 5. SEM images of surface of the films based on: A thermoplastic starch (TPS), B TPS + natural montmorillonite (TPS + NMnt), C TPS + natural montmorillonite containing Jamaica flower extract (TPS + NMnt + JFE), D TPS + montmorillonite modified with dimethyl benzylhydrogenated tallow ammonium (TPS + MntMB), E TPS + montmorillonite modified with dimethyl benzylhydrogenated tallow ammonium containing Jamaica flower extract (TPS + MntMB + JFE), F TPS + montmorillonite modified with dimethyl dihydrogenated tallow ammonium (TPS + MntMD) and G TPS + montmorillonite modified with dimethyl dihydrogenated tallow ammonium containing Jamaica flower extract (TPS + MntMD + JFE). At $500 \times$ of magnification.

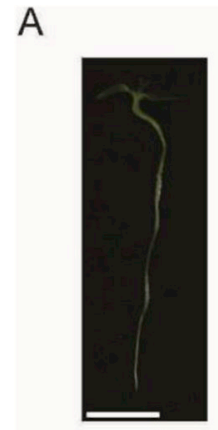

$\mathrm{H}_{2} \mathrm{O}$

B
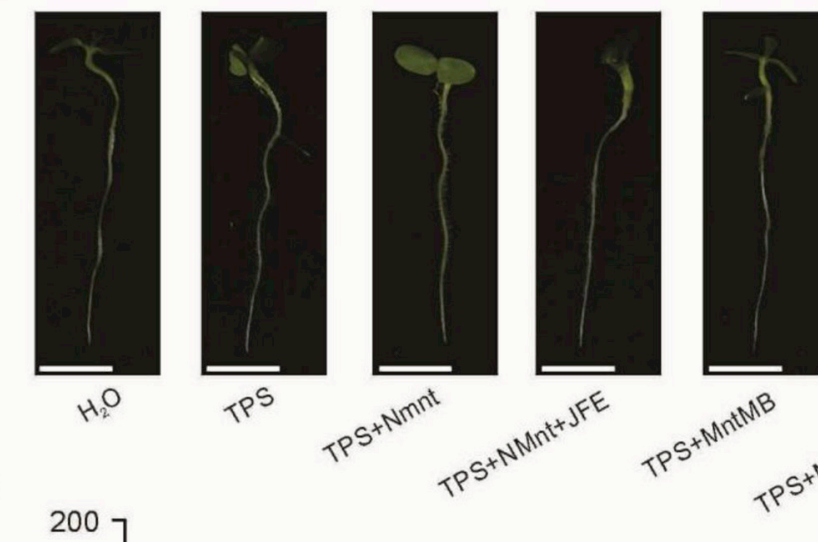

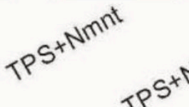

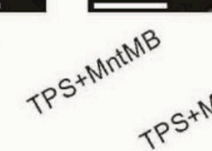
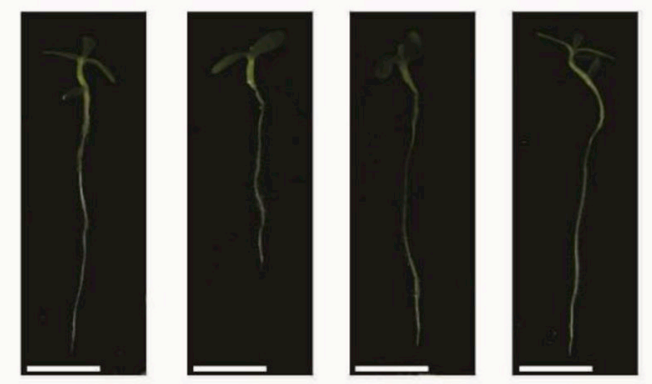<smiles>C[14CH]</smiles><smiles>[CH][14CH2][14CH3]</smiles>

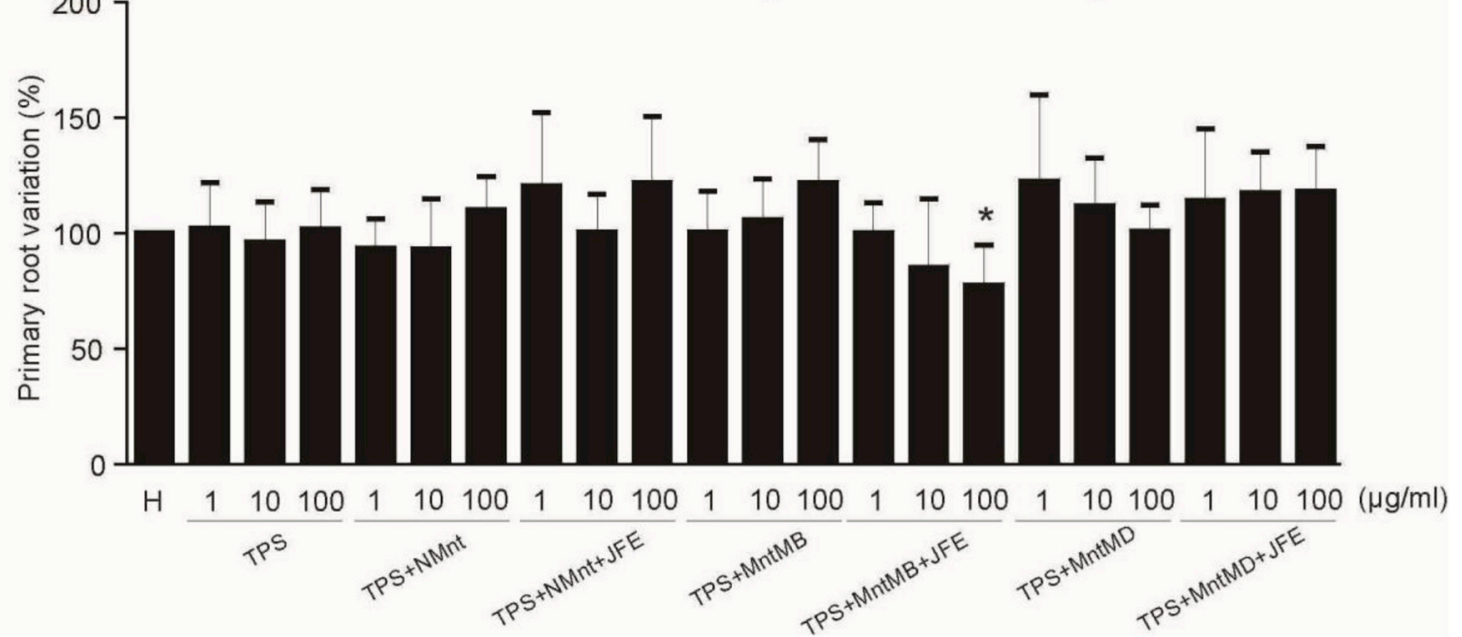

Fig. 6. Compostability study of each analyzed film system using the primary root variation (\%) in lettuce (Lactuca sativa) seedlings germinated on $0.8 \%$ agar- $\mathrm{H}_{2} \mathrm{O}$ in Petri plates. Panel A- Representative image of the lettuce seedlings treated with each film systems at a concentration of $100 \mu \mathrm{g} / \mathrm{mL}(\mathrm{Bars}=1 \mathrm{~cm})$. Panel BMeasurement of primary root variation in lettuce seedlings at different film concentrations: 1,10 and $100 \mu \mathrm{g} / \mathrm{mL}$. The data are expressed as a percentage with respect to the control system (film without natural nanofillers - TPS). Values are the mean ( \pm SD) of three independent experiments. Asterisk indicates statistically significant differences respect to control. Film systems: thermoplastic starch (TPS), TPS + natural montmorillonite (TPS + NMnt), TPS + natural montmorillonite containing Jamaica flower extract (TPS + NMnt + JFE), TPS + montmorillonite modified with dimethyl benzylhydrogenated tallow ammonium (TPS + MntMB), TPS + montmorillonite modified with dimethyl benzylhydrogenated tallow ammonium containing Jamaica flower extract (TPS + MntMB + JFE), TPS + montmorillonite modified with dimethyl dihydrogenated tallow ammonium (TPS + MntMD) and TPS + montmorillonite modified with dimethyl dihydrogenated tallow ammonium containing Jamaica flower extract (TPS + MntMD + JFE).

3.6. Biodegradability in vegetable compost \& variation in the primary root growth of lettuce (Lactuca sativa) seedlings as an ecotoxicity bioassay

Studies of biodegradability and compostability have been little studied in TPS-based films, since many authors have presumed that the native or modified starch matrices and nano-fillers (clay, cellulose and inorganic nanoparticles) added intentionally to reinforce the polymer matrix do not cause any harm to the environment. Our research group, however, has recently shown that it is not only important that these TPS-based materials are biodegradable, but also that they are compostable, i.e. they must disintegrate to reduced particle sizes, and these particles should not cause ecotoxic damage (Gutiérrez, León, et al., 2018). In this study we did not find any statistically significant differences ( $p \geq 0.05$ ) in the biodegradability of the film systems tested over 
the experimentation period (90 days). In fact, after 90 days all the materials studied had completely (100\%) biodegraded. In contrast, Pereira, Abreu, Oliveira, Nobrega, and Machado (2014) reported 20\% biodegradation after 80 days in films made from polylactic acid (PLA) and approximately $40 \%$ for PLA films with an added nano-clay (Cloisite 30B). These authors suggested that the nano-fillers increased the molar volume of the bionanocomposite films, thus making it easier for soil microorganisms to penetrate into the polymer structure, leading to a higher biodegradation rate. This effect was not observed in this study as all the films studied were totally biodegraded.

In order to evaluate the compostability of the manufactured materials and determine their potential ecotoxic effect, known amounts of the developed bionanocomposite films were added as composting materials for seedlings of a well-known food crop, lettuce (Lactuca sativa). Interestingly, we observed that the length of the primary roots of the seedlings planted with a concentration of $100 \mu \mathrm{g} / \mathrm{mL}$ of the TPS + MntMB + JFE film (Fig. 6) were significantly shorter ( $p \leq 0.05)$ than the roots of the seedlings planted using the other film systems as composting materials. This was unsurprising as previously our research group had found that the MntMB + JFE nano-filler showed high cytotoxicity using the normal human lung fibroblast (MRC-5, ATCC CCL171)-cell line as a test material (see Appendix A and B) (Gutiérrez, León, et al., 2018). This led us to reach the following conclusions: 1 ) the cytotoxicity of any nano-filler should be compulsorily evaluated before using it as a reinforcing material in polymeric matrices, and those shown to be cytotoxic should preferably be avoided, and 2) the accumulation of these reinforcement materials, especially the MntMB + JFE nano-filler, could have a negative impact on the vegetation giving them a limited compostability rating in spite of the fact that they are biodegradable.

Finally, more in-depth studies should be conducted to determine the compostability of films derived from carbohydrate polymers containing nano-fillers in order to answer the following questions: 1) is their ecotoxicity in soil systems reversible or irreversible? and 2) even when seedling root growth is not affected could the cytotoxins be incorporated, concentrated, and maintained in the seedlings?

\section{Conclusions}

Films prepared from thermoplastic starch (TPS) containing nanofillers packaged with Jamaica flower extract (JFE, Hibiscus sabdariffa) strengthened hydrogen $(\mathrm{H})$-bonding interactions below the surface of the materials compared to films containing the same nano-fillers but without JFE. The JFE strengthened the H-bonding interactions while maintaining low steric impediments. Stronger H-bonding interactions produced higher water contact angle values and higher total surface energy in the bionanocomposite films. This suggests that stronger $\mathrm{H}$ bonding interactions result in more hydrophobic materials with rougher surfaces. The films containing the MntMB + JFE nano-filler (montmorillonite (Mnt) modified with dimethyl benzylhydrogenated tallow ammonium plus JFE) were biodegradable but non-compostable. These results confirm that not all biodegradable material is environmentally friendly.

\section{Conflicts of interest}

The authors declare no conflict of interest.

\section{Acknowledgements}

The authors would like to thank the Consejo Nacional de Investigaciones Científicas y Técnicas (CONICET) (Postdoctoral fellowship internal PDTS-Resolution 2417), Universidad Nacional de Mar del Plata for financial support. Also, Dr. Mirian Carmona-Rodríguez for her valuable contribution. Many thanks also to Andres Torres Nicolini for all the assistance he provided in this research.

\section{Appendix A. Supplementary data}

Supplementary data to this article can be found online at https:// doi.org/10.1016/j.foodhyd.2018.10.058.

\section{References}

Aphibanthammakit, C., Nigen, M., Gaucel, S., Sanchez, C., \& Chalier, P. (2018). Surface properties of Acacia Senegal vs Acacia seyal films and impact on specific functionalities. Food Hydrocolloids, 82, 519-533. https://doi.org/10.1016/j.foodhyd.2018.04. 032.

Association of Official Analytical Chemists (AOAC) (1990). Official methods of analysis.

ASTM D5338 - 98 (2003). Standard test method for determining aerobic biodegradation of plastic materials under controlled composting conditions. Retrieved from https:// www.astm.org/DATABASE.CART/HISTORICAL/D5338-98R03.htm.

ASTM D6400 - 04 (2004). Standard specification for compostable plastics. Retrieved from https://www.astm.org/DATABASE.CART/HISTORICAL/D6400-04.htm.

Bourtoom, T., \& Chinnan, M. S. (2008). Preparation and properties of rice starch-chitosan blend biodegradable film. Lebensmittel-Wissenschaft und-Technologie- Food Science and Technology, 41(9), 1633-1641. https://doi.org/10.1016/j.lwt.2007.10.014.

Bracone, M., Merino, D., González, J., Alvarez, V. A., \& Gutiérrez, T. J. (2016). Nanopackaging from natural fillers and biopolymers for the development of active and intelligent films. In S. Ikram, \& S. Ahmed (Eds.). Natural polymers: Derivatives, blends and composites (pp, 119-155). New York: Nova Science Publishers.

Chung, Y.-L., Ansari, S., Estevez, L., Hayrapetyan, S., Giannelis, E. P., \& Lai, H.-M. (2010). Preparation and properties of biodegradable starch-clay nanocomposites. Carbohydrate Polymers, 79(2), 391-396. https://doi.org/10.1016/j.carbpol.2009.08. 021.

Cyras, V. P., Manfredi, L. B., Ton-That, M.-T., \& Vázquez, A. (2008). Physical and mechanical properties of thermoplastic starch/montmorillonite nanocomposite films. Carbohydrate Polymers, 73(1), 55-63. https://doi.org/10.1016/j.carbpol.2007.11. 014.

Dang, K. M., \& Yoksan, R. (2015). Development of thermoplastic starch blown film by incorporating plasticized chitosan. Carbohydrate Polymers, 115, 575-581. https://doi. org/10.1016/j.carbpol.2014.09.005.

EN 13432 (2000). Packaging - requirements for packaging recoverable through composting and biodegradation - test scheme and evaluation criteria for the final acceptance of packaging. Retrieved from https://www.en-standard.eu/csn-en-13432 packaging-requirements-for-packaging-recoverable-through-composting-andbiodegradation-test-scheme-and-evaluation-criteria-for-the-final-acceptance-of packaging/.

EN 14995 (2006). Plastics - evaluation of compostability - test scheme and specifications. Retrieved from https://www.en-standard.eu/csn-en-14995-plastics-evaluation-ofcompostability-test-scheme-and-specifications/.

Gao, Y., Dai, Y., Zhang, H., Diao, E., Hou, H., \& Dong, H. (2014). Effects of organic modification of montmorillonite on the performance of starch-based nanocomposite films. Applied Clay Science, 99, 201-206. https://doi.org/10.1016/j.clay.2014.06. 033.

González Seligra, P., Eloy Moura, L., Famá, L., Druzian Janice, I., \& Goyanes, S. (2016). Influence of incorporation of starch nanoparticles in PBAT/TPS composite films. Polymer International, 65(8), 938-945. https://doi.org/10.1002/pi.5127.

Gutiérrez, T. J. (2018a). Active and intelligent films made from starchy sources/blackberry pulp. Journal of Polymers and the Environment, 26(6), 2374-2391. https://doi. org/10.1007/s10924-017-1134-y.

Gutiérrez, T. J. (2018b). Are modified pumpkin flour/plum flour nanocomposite films biodegradable and compostable? Food Hydrocolloids, 83C, 397-410. https://doi.org/ https://doi.org/10.1016/j.foodhyd.2018.05.035.

Gutiérrez, T. J. (2018c). Antibiofilm enzymes as an emerging technology for food quality and safety. In M. Kuddus (Ed.). Enzymes in food biotechnology: Production, applications, and future prospects(1st ed.). Academic Presshttps://doi.org/10.1016/B978-0-12813280-7.00019-0.

Gutiérrez, T. J., \& Alvarez, V. A. (2017). Eco-friendly films prepared from plantain flour/ PCL blends under reactive extrusion conditions using zirconium octanoate as a catalyst. Carbohydrate Polymers, 178, 260-269. https://doi.org/10.1016/j.carbpol.2017. 09.026.

Gutiérrez, T. J., \& Alvarez, V. A. (2018). Bionanocomposite films developed from corn starch and natural and modified nano-clays with or without added blueberry extract. Food Hydrocolloids, 77, 407-420. https://doi.org/10.1016/j.foodhyd.2017.10.017.

Gutiérrez, T. J., \& González, G. (2017). Effect of cross-linking with Aloe vera gel on surface and physicochemical properties of edible films made from plantain flour. Food Biophysics, 12(1), 11-22. https://doi.org/10.1007/s11483-016-9458-z.

Gutiérrez, T. J., Herniou-Julien, C., Álvarez, K., \& Alvarez, V. A. (2018a). Structural properties and in vitro digestibility of edible and $\mathrm{pH}$-sensitive films made from Guinea arrowroot starch and wastes from wine manufacture. Carbohydrate Polymers, 184, 135-143. https://doi.org/10.1016/j.carbpol.2017.12.039.

Gutiérrez, T. J., León, I. E., Ponce, A. G., \& Alvarez, V. A. (2018b). Stabilizing effect of montmorillonite on anthocyanins extracted from Jamaica (Hibiscus sabdariffa)

flowers: Characterization and assessment of cytotoxicity. Food Packaging and Shelf Life (in press).

Gutiérrez, T. J., Ollier, R., \& Alvarez, V. A. (2018c). Surface properties of thermoplastic starch materials reinforced with natural fillers. In V. K. Thakur, \& M. K. Thakur (Eds.). Functional biopolymers (pp. 131-158). Springer International Publishing. https://doi.org/10.1007/978-3-319-66417-0 5.

Gutiérrez, T. J., Suniaga, J., Monsalve, A., \& García, N. L. (2016). Influence of beet flour 
on the relationship surface-properties of edible and intelligent films made from native and modified plantain flour. Food Hydrocolloids, 54, 234-244. https://doi.org/10. 1016/j.foodhyd.2015.10.012.

Gutiérrez, T. J., Tapia, M. S., Pérez, E., \& Famá, L. (2015). Edible films based on native and phosphated 80:20 waxy:normal corn starch. Starch Staerke, 67(1-2), 90-97. https://doi.org/10.1002/star.201400164.

Hernández, O., Emaldi, U., \& Tovar, J. (2008). In vitro digestibility of edible films from various starch sources. Carbohydrate Polymers, 71(4), 648-655. https://doi.org/10. 1016/j.carbpol.2007.07.016.

Iman, M., \& Maji, T. K. (2012). Effect of crosslinker and nanoclay on starch and jute fabric based green nanocomposites. Carbohydrate Polymers, 89(1), 290-297. https://doi. org/10.1016/j.carbpol.2012.03.012.

ISO 14855-1:2005 (2005). Determination of the ultimate aerobic biodegradability of plastic materials under controlled composting conditions - Method by analysis of evolved carbon dioxide - Part 1: General method. Retrieved from https://www.iso. org/standard/42155.html.

ISO 14855-2:2007 (2007). Determination of the ultimate aerobic biodegradability of plastic materials under controlled composting conditions - Method by analysis of evolved carbon dioxide - Part 2: Gravimetric measurement of carbon dioxide evolved in a laboratory-scale test. Retrieved from https://www.iso.org/standard/40617.html.

Lee, S.-R., Park, H.-M., Lim, H., Kang, T., Li, X., Cho, W.-J., et al. (2002). Microstructure, tensile properties, and biodegradability of aliphatic polyester/clay nanocomposites. Polymer, 43(8), 2495-2500. https://doi.org/10.1016/S0032-3861(02)00012-5.

Liu, F., Avena-Bustillos, R. J., Chiou, B.-S., Li, Y., Ma, Y., Williams, T. G., ... Zhong, F. (2017). Controlled-release of tea polyphenol from gelatin films incorporated with different ratios of free/nanoencapsulated tea polyphenols into fatty food simulants. Food Hydrocolloids, 62, 212-221. https://doi.org/10.1016/j.foodhyd.2016.08.004.

Lopez, O., Garcia, M. A., Villar, M. A., Gentili, A., Rodriguez, M. S., \& Albertengo, L. (2014). Thermo-compression of biodegradable thermoplastic corn starch films containing chitin and chitosan. Lebensmittel-Wissenschaft und -Technologie- Food Science and Technology, 57(1), 106-115. https://doi.org/10.1016/j.lwt.2014.01.024.

Mendes, J. F., Paschoalin, R., Carmona, V. B., Sena Neto, A. R., Marques, A. C. P., Marconcini, J. M., ... Oliveira, J. E. (2016). Biodegradable polymer blends based on corn starch and thermoplastic chitosan processed by extrusion. Carbohydrate Polymers, 137, 452-458. https://doi.org/10.1016/j.carbpol.2015.10.093.
Owens, D. K. (1970). Some thermodynamic aspects of polymer adhesion. Journal of Applied Polymer Science, 14(7), 1725-1730. https://doi.org/10.1002/app.1970. 070140706.

Pereira, M., Abreu, A. S., Oliveira, M., Nobrega, J. M., \& Machado, A. V. (2014). Biodegradable nanocomposite for food packaging application. XIV SLAP-simpósio latino americano de Polímeros (pp. 1-4). Associação Brasileira de Polímeros. Retrieved from https://repositorium.sdum.uminho.pt/bitstream/1822/34759/1/Nobrega 1. pdf.

Romero-Bastida, C. A., Bello-Pérez, L. A., Velazquez, G., \& Alvarez-Ramirez, J. (2015) Effect of the addition order and amylose content on mechanical, barrier and structural properties of films made with starch and montmorillonite. Carbohydrate Polymers, 127, 195-201. https://doi.org/10.1016/j.carbpol.2015.03.074.

Shi, R., Zhang, Z., Liu, Q., Han, Y., Zhang, L., Chen, D., et al. (2007). Characterization of citric acid/glycerol co-plasticized thermoplastic starch prepared by melt blending. Carbohydrate Polymers, 69(4), 748-755. https://doi.org/10.1016/j.carbpol.2007.02. 010.

Suárez, G., \& Gutiérrez, T. (2017). Recent advances in the development of biodegadable films and foams from cassava starch. In C. Klein (Ed.). Handbook on cassava: Production, potential uses and recent advances (pp. 297-312). New York: Nova Science Publishers, Inc.

Toro-Márquez, L. A., Merino, D., \& Gutiérrez, T. J. (2018). Bionanocomposite films prepared from corn starch with and without nanopackaged Jamaica (Hibiscus sabdariffa) flower extract. Food and Bioprocess Technology, 11(11), 1955-1973. https:// doi.org/10.1007/s11947-018-2160-z.

Vogler, E. A. (1998). Structure and reactivity of water at biomaterial surfaces. Advances in Colloid and Interface Science, 74(1-3), 69-117. https://doi.org/10.1016/S00018686(97)00040-7.

Wenzel, R. N. (1936). Resistance of solid surfaces to wetting by water. Industrial and Engineering Chemistry, 28(8), 988-994. https://doi.org/10.1021/ie50320a024.

Yan, Q., Hou, H., Guo, P., \& Dong, H. (2012). Effects of extrusion and glycerol content on properties of oxidized and acetylated corn starch-based films. Carbohydrate Polymers, 87(1), 707-712. https://doi.org/10.1016/j.carbpol.2011.08.048.

Zhang, Y.-R., Wang, X.-L., Zhao, G.-M., \& Wang, Y.-Z. (2013). Influence of oxidized starch on the properties of thermoplastic starch. Carbohydrate Polymers, 96(1), 358-364. https://doi.org/10.1016/j.carbpol.2013.03.093. 